agulant peptide (TAP) expressed in the methylotrophic yeast Pichia pastoris. Bio Technology, 1994, 12: 1 119 1124

4 Roa M, Blobel G. Biosynthesis of peroximal enzymes in the methylotrophic yeast Hansenula polymorpha. Proc Natl Acad Sci USA, 1983, 80: $6872 \sim 6876$

5 Couderc R, Baratti J. Oxidation of methanol by the yeast Pichia postoris. Purification and properties of alcohol oxidase. Agric Biol Chem, 1980, 44: 2 279 2285

6 Cregg J M, Vedvick T S, Raschkek W C. Recent advances in the expression of foreign genes in Pichia pastoris. Bio Technol ogy, 1993, 11; 905 910

7 Clare J J, Romanos M A, Rayment F B, et al. Production of mouse epidermal grow th factor in yeast: high level secretion us ing Pichia pastoris strains containing multipl gene copies. Gene, 1991, 105: 205 212

8 Scoer C A, Clare J J, M cCombie W R, et al. Rapid selection using G418 of high copy number transformants of Pichia pastoris for high_level foreign gene. Bio T echnology, 1994, 12: 181 184

9 Romanos M A, Scoer C A, Clare J J. Foreign gene expression in yeast: a review. Yeast, 1992, 8: 423 488

10 Thill G P. Davis G R. Stillman C. et al. Positive and negative effects of mult iconv intergrated ex nression vectors on nrotein expression in Pichia pastoris. In: Davies J, Florent J eds. Proceedings of the 6th Intemational Symposium on Genetics of M r croorganisms, Vol 루) Paris: Societe Franscaise de Microbiologie, 1990, 477 490

11 Despreaux C W, Manning R F. The dacA gene of Bacillus stearothermophilus coding for D_alanine carboxypeptidase: cloning structure and expression in Escherichia coli and Pichia pastoris. Gene, 1993, 131: 35 41

\title{
$\mathrm{Na}^{+}, \mathrm{K}^{+} / \mathrm{Cl}^{-}, \mathrm{SO}_{4}^{2-}, \mathrm{NO}_{3}^{-}-\mathrm{H}_{2} \mathrm{O}$ 五元体系 的卤水-矿物平衡研究
}

\section{李亚文 韩蔚田}

(中国地质大学, 北京 100083)

摘要＼cjkstart在我国新疆罗布泊、吐鲁番等地区广泛分布含硝酸盐的盐湖、盐滩,近年来也发现一些小型的硝酸盐矿 床。根据罗布泊等地区已发现的盐类矿物组合分析, 该地区盐湖的卤水-矿物平衡应属 $\mathrm{K}^{+}, \mathrm{Na}^{+} / \mathrm{Cl}^{-}, \mathrm{SO}_{4}^{2-}$, $\mathrm{NO}_{3}^{-}-\mathrm{H}_{2} \mathrm{O}$ 五元水盐体系。本文用等温溶度法研究了该体系 $25^{\circ} \mathrm{C}$ 时的卤水-矿物平衡, 得到 15 个平衡点的数 据(其中有 4 个是五元零变度点), 绘制出等温相图, 并对该相图的特征做了分析. 说明了在 9 条相区界线中 8 条都是共结线, 仅有一条是反应线。该等温图中有两个共结点, 也是 $\mathrm{H}_{2} \mathrm{O}$ 值的最低点和卤水蒸发的必然干 点.

\section{关键词 硝酸盐 罗布泊 卤水-矿物平衡}

世界上硝酸盐钾盐沉积比较罕见, 著名的仅有智利的硝酸盐矿床 ${ }^{[1]}$. 我国新疆罗布泊、 吐鲁番等地区位于大陆腹地, 气候极干旱, 含硝酸盐的盐湖、盐滩广泛分布 ${ }^{[2]}$, 近年来在罗布 泊地区以及吐鲁番乌尊布拉克盐湖发现的一系列小型的硝酸盐矿床, 目前已被开采利用 ${ }^{3]}$, 用于生产硝酸钠和硝酸钾.

根据罗布泊等地区已发现的盐类矿物组合分析, 其卤水-矿物平衡体系主要包含 $\mathrm{K}^{+}$, $\mathrm{Na}^{+}, \mathrm{Mg}^{2+}, \mathrm{Cl}^{-}, \mathrm{SO}_{4}^{2-}$ 和 $\mathrm{NO}_{3}^{-} 6$ 种组分. 若考虑到含 $\mathrm{Mg}$ 的盐类矿物比较少见, 则该地区盐 湖的卤水-矿物平衡应属 $\mathrm{K}^{+}, \mathrm{Na}^{+} / \mathrm{Cl}^{-}, \mathrm{SO}_{4}^{2-}, \mathrm{NO}_{3}^{-}-\mathrm{H}_{2} \mathrm{O}$ 五元水盐体系. 该五元体系包含着 
以下 5 个四元体系: ( ) $\mathrm{Na}^{+} / \mathrm{Cl}^{-}, \mathrm{SO}_{4}^{2-}, \mathrm{NO}_{3}^{-}-\mathrm{H}_{2} \mathrm{O} ;(\quad) \mathrm{K}^{+} / \mathrm{Cl}^{-}, \mathrm{SO}_{4}^{2-}, \mathrm{NO}_{3}^{-}-\mathrm{H}_{2} \mathrm{O} ; \quad$ ） $\mathrm{K}^{+}, \mathrm{Na}^{+} / \mathrm{Cl}^{-}, \mathrm{SO}_{4}^{2-},-\mathrm{H}_{2} \mathrm{O} ;(\quad) \mathrm{K}^{+}, \mathrm{Na}^{+} / \mathrm{Cl}^{-}, \mathrm{NO}_{3}^{-}-\mathrm{H}_{2} \mathrm{O} ;(\quad) \mathrm{K}^{+}, \mathrm{Na}^{+} / \mathrm{SO}_{4}^{2-}, \mathrm{NO}_{3}^{-}-\mathrm{H}_{2} \mathrm{O}$. 其中四元体系已有文献资料 ${ }^{[4,5]}$, 而含硝酸盐的五元体系至今未见报道过. 本文用等温溶度法 研究了 $\mathrm{K}^{+}, \mathrm{Na}^{+} / \mathrm{Cl}^{-}, \mathrm{SO}_{4}^{2-}, \mathrm{NO}_{3}^{-}-\mathrm{H}_{2} \mathrm{O}$ 五元体系 $25^{\circ} \mathrm{C}$ 时的卤水-矿物平衡, 绘制出等温相图, 并对 该相图的特征做了分析.

在实验中平衡液相的组成用化学分析法测定: $\mathrm{K}^{+}$用四苯嗍钠重量法; $\mathrm{SO}_{4}^{2-}$ 用 $\mathrm{BaSO}_{4}$ 重 量法; $\mathrm{NO}_{3}^{-}$用还原蒸馏法测定; $\mathrm{Cl}^{-}$用硝酸银容量法; $\mathrm{Na}^{+}$由差减法求得. 固相组成用偏光显 微镜根据矿物晶体的光性和折光率鉴定. 实验结果见表 1. 并绘成对 $\mathrm{NaCl}$ 饱和的 $2 \mathrm{NO}_{3}-$ $\mathrm{SO}_{4}-2 \mathrm{~K}$ 正三角坐标图( 图 1).

表 $1 \mathrm{~K}^{+}, \mathrm{Na}^{+} / \mathrm{Cl}^{-}, \mathrm{SO}_{4}^{2-}, \mathrm{NO}_{3}^{-}-\mathrm{H}_{2} \mathrm{O}$ 五元体系 $25^{\circ} \mathrm{C}$ 时溶解度数据

\begin{tabular}{|c|c|c|c|c|c|c|c|c|c|c|c|}
\hline \multirow{2}{*}{$\begin{array}{l}\text { 平 } \\
\text { 衡 } \\
\text { 点 }\end{array}$} & \multicolumn{6}{|c|}{$\begin{array}{l}\text { 液 相 组 成 } \\
\text { (重量百分比) }\end{array}$} & \multicolumn{4}{|c|}{$\begin{array}{c}\text { 相 图 指 数 } \\
2 \mathrm{~K}+2 \mathrm{NO}_{3}+\mathrm{SO}_{4}=100 \mathrm{M}\end{array}$} & \multirow{2}{*}{ 平衡固相 } \\
\hline & $\mathrm{Na}^{+}$ & $\mathrm{K}^{+}$ & $\mathrm{NO}_{3}^{-}$ & $\mathrm{SO}_{4}^{2-}$ & $\mathrm{Cl}^{-}$ & $\mathrm{H}_{2} \mathrm{O}$ & $2 \mathrm{~K}$ & $2 \mathrm{NO}_{3}$ & $\mathrm{SO}_{4}$ & $\mathrm{H}_{2} \mathrm{O}$ & \\
\hline a & 10.08 & 2. 85 & - & 5.26 & 14. 24 & 67.57 & 39.96 & - & 60.04 & 4114 & $\mathrm{H}+\mathrm{T}+\mathrm{Gl}$ \\
\hline b & 8.22 & 5.93 & - & 1.60 & 16.86 & 67.40 & 82.00 & - & 18.00 & 4052 & $\mathrm{H}+\mathrm{Gl}+\mathrm{Syl}$ \\
\hline c & 8.15 & 9.31 & 14. 18 & - & 12.91 & 55.44 & 51.02 & 48.98 & - & 1319 & $\mathrm{H}+\mathrm{Syl}+\mathrm{Ni}$ \\
\hline d & 11.29 & 6.91 & 30.50 & - & 6.23 & 45.07 & 26.42 & 73.58 & - & 749.1 & $\mathrm{H}+\mathrm{Ni}+\mathrm{So}$ \\
\hline $\mathrm{e}$ & 13.84 & - & 22.04 & 1. 32 & 7.76 & 55.04 & - & 92.81 & 7. 19 & 1597 & $\mathrm{H}+\mathrm{So}+\mathrm{Da}$ \\
\hline $\mathrm{f}$ & 12.80 & - & 12.93 & 3.12 & 10.04 & 61.11 & - & 76. 24 & 23.76 & 2483 & $\mathrm{H}+\mathrm{Da}+\mathrm{T}$ \\
\hline g & 12.79 & 3.33 & 26. 30 & 1. 18 & 6.83 & 49.56 & 15.97 & 79.42 & 4. 61 & 1031 & $\mathrm{H}+\mathrm{So}+\mathrm{Da}$ \\
\hline h & 9.82 & 8.09 & 19.78 & 1.59 & 10.00 & 50.72 & 37.01 & 57.07 & 5.92 & 1008 & $\mathrm{H}+\mathrm{Gl}+\mathrm{Ni}$ \\
\hline $\mathrm{i}$ & 10.63 & 4. 29 & 10.93 & 3.83 & 11.20 & 59.12 & 29.99 & 48.21 & 21.80 & 1797 & $\mathrm{H}+\mathrm{T}+\mathrm{Gl}$ \\
\hline $\mathrm{j}$ & 8.27 & 7. 60 & 6.89 & 1.31 & 14.74 & 61.18 & 58.40 & 33.39 & 8.21 & 2042 & $\mathrm{H}+\mathrm{Gl}+\mathrm{Syl}$ \\
\hline k & 11.49 & 6.98 & 30.33 & 1.05 & 5.93 & 44.22 & 25.90 & 70.93 & 3.17 & 712.5 & $\mathrm{H}+\mathrm{Da}+\mathrm{So}+\mathrm{Ni}$ \\
\hline 1 & 10.54 & 7. 37 & 23.70 & 2. 10 & 7. 84 & 48.44 & 30.68 & 62.19 & 7. 13 & 875.8 & $\mathrm{H}+\mathrm{Ni}+\mathrm{Da}+\mathrm{Gl}$ \\
\hline $\mathrm{m}$ & 10.29 & 5.33 & 9.47 & 17. 50 & 3.32 & 54.09 & 27.95 & 57.87 & 14. 17 & 1232 & $\mathrm{H}+\mathrm{T}+\mathrm{Gl}+\mathrm{Da}$ \\
\hline $\mathrm{p}$ & 8.01 & 9.60 & 12. 51 & 14. 24 & 1.11 & 54.53 & 49.27 & 46.09 & 4. 64 & 1216 & $\mathrm{H}+\mathrm{Gl}+\mathrm{Ni}+\mathrm{Syl}$ \\
\hline$r$ & 8.09 & 9.38 & 12.54 & 14.05 & 1.11 & 54.83 & 49.00 & 46.28 & 4.72 & 1244 & $\mathrm{H}+\mathrm{Gl}+\mathrm{Ni}$ \\
\hline
\end{tabular}

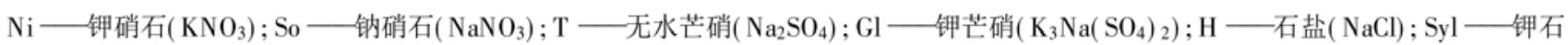
盐 $(\mathrm{KCl}) ; \mathrm{Da}$ 一钠硝矾 $\left(\mathrm{NaNO}_{3} \cdot \mathrm{Na}_{2} \mathrm{SO}_{4} \cdot \mathrm{H}_{2} \mathrm{O}\right)$

表 1 中共列出 15 个平衡点的数据, 其中 6 个点 $(a, b, c, d, e, f)$ 为边界四元体系; 在五元体 系的单变度线上有 5 个点 $(g, h, i, j, r)$; 另外有 4 个是五元零变度点 $(k, l, m, p)$.

在图 1 中共有 6 种矿物的相区, 分别为: 无水芒硝 $\mathrm{Na}_{2} \mathrm{SO}_{4}(\mathrm{~T})$ 、钾芒硝 $\mathrm{K}_{3} \mathrm{Na}\left(\mathrm{SO}_{4}\right)_{2}$ $(\mathrm{Gl})$ 、钾石盐 $\mathrm{KCl}\left(\mathrm{Sy}_{\mathrm{l}}\right)$ 、钾硝石 $\mathrm{KNO}_{3}(\mathrm{Ni})$ 、钠 硝石 $\mathrm{NaNO}_{3}(\mathrm{So})$ 和钠硝矾 $\mathrm{Na}_{3}\left(\mathrm{NO}_{3}\right)\left(\mathrm{SO}_{4}\right)$ $\mathrm{H}_{2} \mathrm{O}(\mathrm{Da})$.

在图 2 中表示了对该等温图的分析. 根 据切线定理确定了各条相区界线的性质, 9 条 相区界线中 8 条都是共结线, 仅有一条( T/ $\mathrm{Da})$ 是反应线. 连接固相组成点 $\mathrm{Ni}, \mathrm{Da}$ 和 Gl 之间的 3 条直线 (虚线), 将原坐标三角形划分

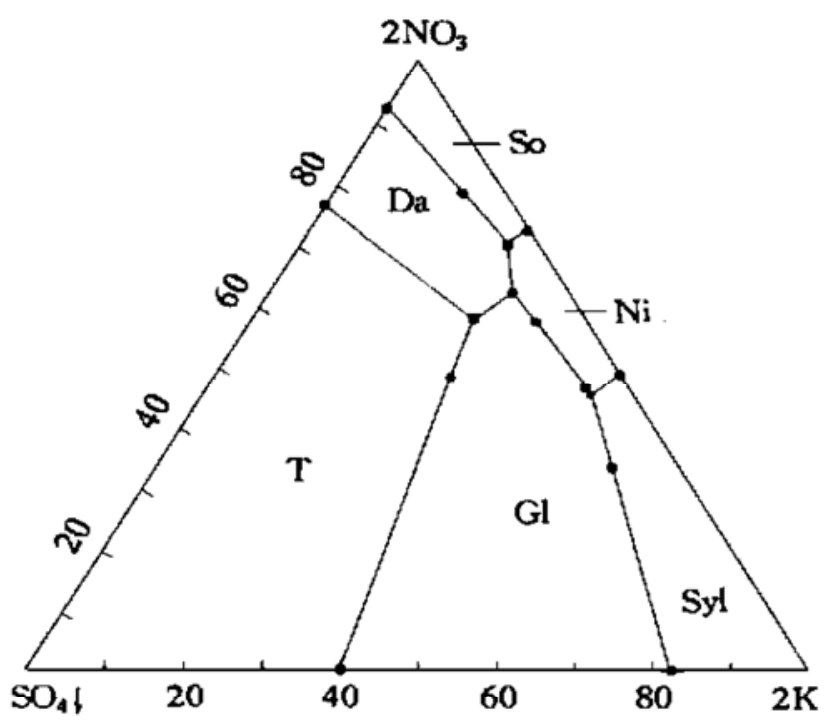

图 $1 \mathrm{~K}^{+}, \mathrm{Na}^{+} / \mathrm{Cl}^{-}, \mathrm{SO}_{4}^{2-}, \mathrm{NO}_{3}^{-}-\mathrm{H}_{2} \mathrm{O}$ 体系 $25{ }^{\circ} \mathrm{C}$ 等温图(对 $\mathrm{NaCl}$ 饱和) 


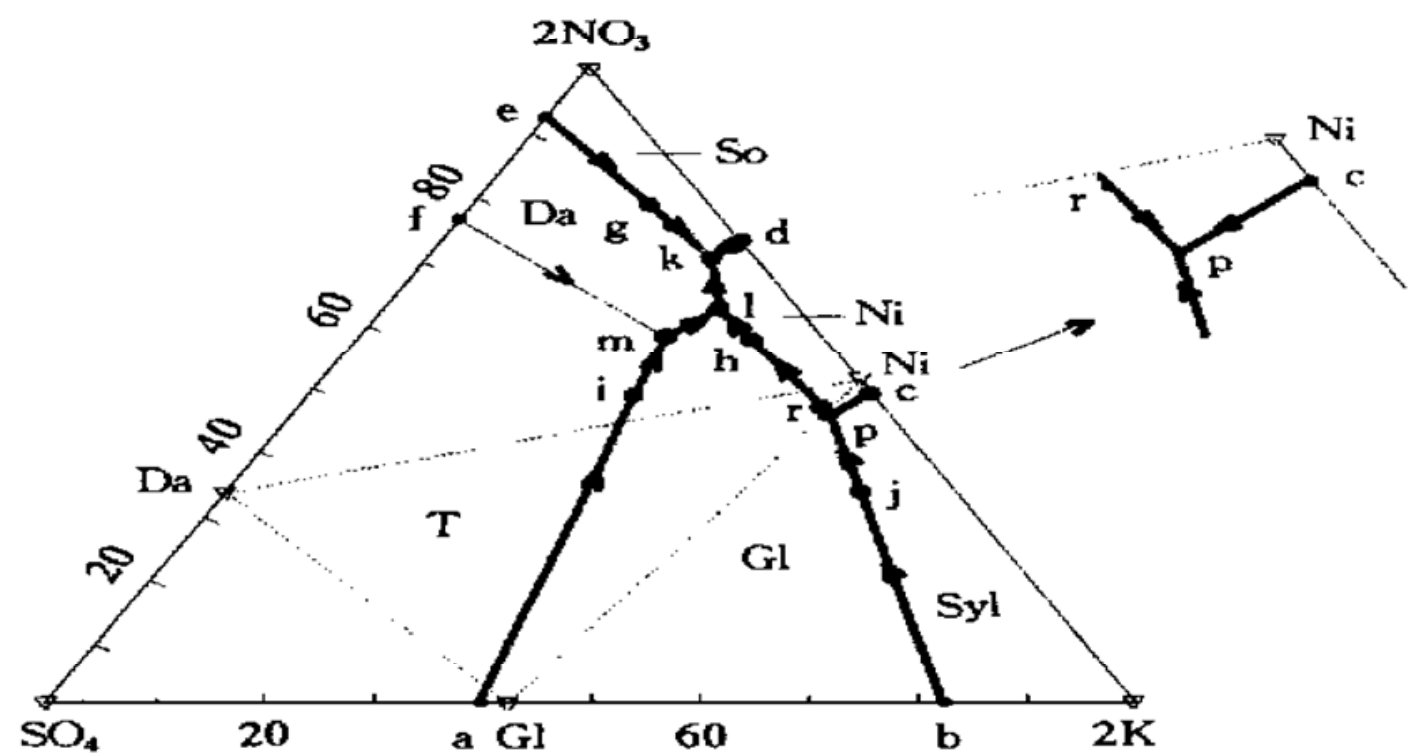

图 2 等温图分析

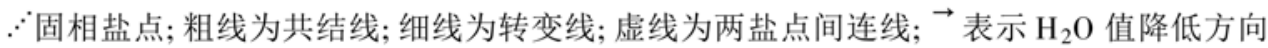

为 4 个副三角形. 每个三角形所表示的 3 种矿物分 别与一个零变度点对应. 根据重心规则判断零变 度点 $\mathrm{l}$ 和 $\mathrm{m}$ 是反应点, $\mathrm{k}$ 和 $\mathrm{p}$ 是共结点. 根据各实 验点相图指数 $\mathrm{H}_{2} \mathrm{O}$ 值的高低, 在图 2 中的相区界 线上用箭头标出了 $\mathrm{H}_{2} \mathrm{O}$ 值降低的方向. 在反应点 $\left(\right.$ 点 $\mathrm{l}, \mathrm{m}$ ) 处 3 条线 $\mathrm{H}_{2} \mathrm{O}$ 值降的特征为 $;$; 在共结 点 $\mathrm{k}$ 处 $\mathrm{H}_{2} \mathrm{O}$ 值降的特征为

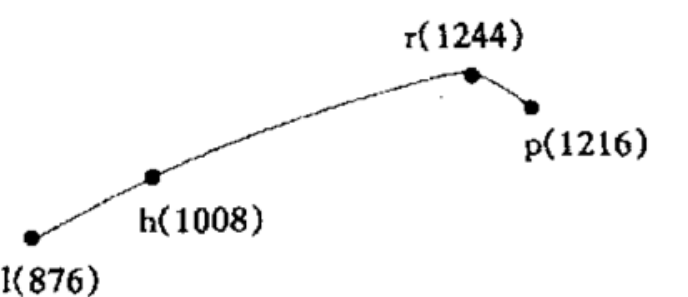

图 $3 \mathrm{pl}$ 线上水值示意图

$\mathrm{H}_{2} \mathrm{O}$ 值的最低点. 由于点 $\mathrm{p}$ 也是共结点, 相交于该点的 $\mathrm{H}_{2} \mathrm{O}$ 值降的特征应和点 $\mathrm{k}$ 相同. 点 $p$ 也应是 $\mathrm{H}_{2} \mathrm{O}$ 值的最低点. 因而可以推论, 在钾芒硝与钾硝石的相区界线 $\mathrm{p}-\mathrm{l}$ 线上, 必定有一个 $\mathrm{H}_{2} \mathrm{O}$ 值的最高点. 理论上该点应位于相区界线 $\mathrm{pr}$ 线与固相组成点 $\mathrm{NrGl}$ 连线的交点 $\mathrm{r}$ 处 (点 $r$ 非常靠近点 $p$ ). 为此补做了点 $r$ 的数据 (表 1), 用实验证实了上述推论 (图 3). 说明了在 $\mathrm{K}^{+}, \mathrm{Na}^{+} / \mathrm{Cl}^{-}, \mathrm{SO}_{4}^{2-}, \mathrm{NO}_{3}^{-}-\mathrm{H}_{2} \mathrm{O}$ 五元体系 $25^{\circ} \mathrm{C}$ 等温图中有 2 个共结点, 也是 $\mathrm{H}_{2} \mathrm{O}$ 值的最低点 和卤水蒸发的必然干点.

致谢 本工作为国家自然科学基金( 批准号: 49503045) 资助项目.

\section{参 考 文 献}

1 Ericksen G E, Geology and origin of the Chilean nitrate deposits, Washington: U S Government Printing office, 1981

2 郑喜玉, 李秉孝, 高章洪, 等. 新疆盐湖. 北京: 科学出版社, 1995

3 蔡克勤, 高建华, 赵德钧, 等. 新疆罗布泊地区水硝碱美矾和钠硝矾的矿物学研究. 矿物学报, 1992(2): 143 151

4 How ard I S. Solubilities of Inorganic and Organic Compounds. London: Oxford University Press, 1979

5 李亚文, 任普亮. $\mathrm{K}, \mathrm{Na} / \mathrm{NO}_{3}, \mathrm{SO}_{4}-\mathrm{H}_{2} \mathrm{O}$ 四元体系 $25^{\circ} \mathrm{C}$ 的溶解度相图. 中国学术期刊文摘(科技快报), 1997( 7)：870 871 